


\section{Ciencia y arte: singularidades} biológicas

\section{Edgar Samaniego Rojas*}

\section{RESUMEN}

Las grandes conquistas de la ciencia y del arte suelen ser ignoradas por los beneficiarios de la gran tramoya financiera de la sociedad; en cambio, los científicos que hacen grandes aportes para el conocimiento y la adaptación del hombre, participan escasamente de sus propios descubrimientos. Mientras el arte es indeterminista y emergente, la ciencia es probabilística y predictible pero, uno y otra se han colapsado ante el enigma del universo y su origen o la emergencia de la vida. El carácter acumulativo y perseverante de la ciencia permite tolerar los horrores mentales que en el pasado la idolatría impuso en la interpretación de las constantes de la naturaleza; sin embargo, el racionalismo crítico con la explosión técnico-científica hicieron factible la aprehensión de la realidad objetiva. El artista no está obligado a demostrar sus abstracciones, la belleza no es exacta. El científico que no liga sus hipótesis al origen causativo de los procesos, volverá a la fabulación vegetativa, la ciencia es precisa en los resultados y sobria en sus convicciones. Arte y ciencia, ciencia y creación son biosingularidades que subyacen en la evolución conciente del pensamiento humano y sólo de el.

\section{ABSTRACT}

Great conquests of science and art tend to be ignored by the beneficiaries of the huge financial scheme of society. Insted, scientists who make great achievements for knowledge and men adaptation, barely participate of their own discoveries. While art is indeterministic and emergent, science is probabilistic and predictable, but both have collapsed to riddle of the universe and its origin or emergence of life. The cumulative and persevering character of science lets it tolerate the mental horrors, that in the past, idolatry imposed in the interpretation of the constants of nature; however, the critical rationalism, with its technical-scientific explosion, made the apprehension of objective reality possible. The artist is not required demonstrate his abstractions, beauty is not exact. The scientist, that doesn't link his hypotesis to the causative origin of processes, will turn back to vegetative fabulation; science is precise in its results and feasible in its convictions. Art and science, science and creation are bio-singularities underlaying in the conscious evolution of human thought, and only in it.

* Dr. Edgar Samaniego Rojas, Rector de la Universidad Central del Ecuador, médico Gineco-Obstetra graduado en la Universidad Central del Ecuador y Máster en Farmacología por la Universidad de Chile. Ha publicado varios estudios e investigaciones entre ellos: Farmacología del Sistema Nervioso Autónomo; Manual de Farmacología Médica; Los medicamentos en el Ecuador, de la realidad a la utopía; entre otros. 
l poeta Fabián Guerrero que se consagró "La Víspera" de sus dolores endecasilábicos, me suscitó la necesidad de ensartar algunas cogitaciones sobre la ciencia - misil que desbroza confidencias continuas hacia el conocimiento de la naturaleza y sus esencias y el arte - sensaciones multimodales asentadas en el consciente del "yo" para modular las melancolías y vivencias crudas-. Acepto y de inmediato reflexiono: si este mes de septiembre del 2011 se reemplazara la mentira antropomórfica de Ptolomeo por la concepción heliocéntrica de Copérnico, Galileo y Kepler, ningún movimiento circular u ondulatorio se produciría entre gerentes de casinos o exportadores bananeros. Similarmente: si en estos días asomara por vez primera la genialidad newtoniana de la atracción gravitatoria de los cuerpos celestes en proporción a la masa, no habrá mueca alguna entre los asambleístas cuya gravitación cimera no excede las contorsiones éticas para su propia peristalsis. Los más, beben de los productos que la ciencia encuentra, que el arte promueve, pero los ignoran en su sustancialidad y compromiso.

A contra gusto de lo dicho: permítase que los astrofísicos de la NASA observen la "Gioconda" o "La virgen de las rocas" estilizadas por da Vinci y se notará la plena mostración intelectiva de hombres superiores, rescatando la virtud armoniosa del talento y genialidad humanas.

Similarmente: tómese un par de células germinativas para que el hibridismo in vitro fusione genes y esperanza, bajo la expectación endoscópica del biólogo molecular; todos los fisiólogos presentes admitirán de suyo, la extensión cósmica del talento humano. Los menos, trabajamos para desmitificar las confidencias de la naturaleza, pero apenas si nos nutrimos de sus excelencias.

El arte como expresión vidente del hombre, es indeterminista y emergente; la

ciencia suele ser predictible y supremamente probabilística objetiva; uno y otra son de latitud infinita, se nutren de la abstracción empírica y crecen con explosión dubitativa; sin embargo, su crecimiento sin límite admite dos obstáculos: el origen del universo y la emergencia de la vida. Cualquier teosimbolismo ocioso obstaculizará el vuelo entregando las dos tareas a dioses autoritarios pero omnipotentes. Los apuros de san Agustín cuando se le preguntó que hacía Dios antes de que crear el universo, dan consistencia a la conclusión vehemente de lo dicho: " Estaba preparando el infierno para quienes hicieran estos cuestionamientos". Más y quizá, al haber la naturaleza cubierto de inusitada perplejidad a esos acontecimientos, es cuestionante la fiabilidad, pertinencia y aprehensión de lo posible humano, de la cercanía a la objetividad cognoscitiva. Muy otro es el compromiso del racionalismo observacional que vía de la "causación ascendente o descendente" busca y encuentra explicación para el origen natural o mórbido de las causas, habida cuenta de que cada cosa (causa) es un pro-

"Estaba preparando el infierno para quienes hicieran estos cuestionamientos" ceso y, los procesos físicos o memorativos consumen sucesiones infinitas o cuantificables de energía y de partículas elementales. En esta línea de reflexión, ninguno de los lectores sufrirá de contracción espiritual cuando recuerde a John Eccles, sabio neurólogo que sustentado en sus mediciones cualicuantitativas de las redes sinápticas del cerebro, sentenció: “El hombre es un ser que reflexiona sobre si mismo porque tiene la capacidad de objetivarse y considerar lo que es y lo que quiere ser. Sólo el hombre tiene conciencia de si mismo y sólo él puede en cierto modo, colocarse fuera de si y contemplarse como un objeto. Al contemplar la naturaleza del hombre, descubro que tengo acceso directo a información privilegiada sobre un individuo, yo mismo con mi autoconciencia”. 
La ciencia no es patrimonio cataclísmico de la mente, no suele verificarse en estampida, tiene engranajes acumulativos y perseverantes, que se consolidan con el tiempo o el tiempo mismo los deprecia, pero siempre deja un retazo y la sumatoria de estos la embellece y descifra. A veces, las más, idolatrías y empirismos que a demérito de la razón, aún sobreviven, condujeron a falsaciones irritantes; sin embargo, guarecen con la fortaleza de haber engranado la investigación en apego a lo real y demostrable. Caben algunas referencias para situarnos en el propósito: Zeus sentenció a Prometeo a permanecer encadenado en una roca por haberse hurtado el fuego que entregó en beneficio de los mortales, un águila debió comerse a picotazos el hígado ubicado en el tórax hasta acabar con el sentenciado. Otra distorsión anatómica obra de la ingenuidad metafísica de los astrónomos grecorromanos, quienes ubicaron el alma en la cercanía tangencial de la glándula pineal. En nuestros tiempos de ciencia acumulativa y lúcida, la disección de piezas biológicas heredada de los antiguos, en asocio con métodos creados en la postmodernidad, como: hibridación in situ, auto radiografía de ligandos por emisión de positrones, clonación de anticuerpos monoclonales, ha confirmado que la abstinencia de receptores colinérgicos en el área cortical, afecta el aprendizaje y la memoria con una relación causal a modelo matemático. Entonces, la fiscalía actual de los procesos pretéritos en ciencia, pueden causar horror mental, que en la tolerancia evolutiva del talento, no es permisible, mas bien, se adhiere al espíritu relativo de la ciencia experimental, en tanto la investigación no provee resultados inmutablemente ciertos, aunque la ciencia tampoco es una bienal de conjeturas.

Más de lo mismo: el Dios Apolo encargó a Quirón, la educación de su hijo Asclepio en tanto este conocía de las virtudes medicinales de las plantas que la naturaleza había sembrado en el monte Citerón. Con tales conocimientos, Asclepio se convirtió en el Dios griego de la salud, devenido en perfecto e inmutable. Estas fabulaciones de la mitología ceden espacio y credibilidad en la Grecia sensata del siglo VI a.C. cuando los filósofos presocráticos (Anaximandro, Heráclito, Orquelao, el mismo Demócrito) sacudieron la cosmogonía mítico-religiosa y la suplantaron con la cosmología filosófica que crea el concepto de physis (naturaleza) en cuya textura subyace el destino total del hombre. Una frase de esa época grafica tal influencia: "Bien instruida y por si misma, la physis sin aprendizaje, hace lo que conviene". Con esa percepción, los astros, las plantas y los animales asumieron supremas virtudes curativas y se consagraron en jornadas históricas demenciales: el excremento de cocodrilo era tan prodigioso para curar la inflamación, el dolor, la diarrea, que al escasear se llegó a falsificarlo. Nuestra quina transeúnte, desde Loja a España, socializada en Europa por los jesuitas alcanzó tal magnitud que se jerarquizó como "objeto precioso" y en homenaje a esa congregación se la denominó: "Pulvis iesuitarum"; sin embargo y a poco, surgieron los detractores: los protestantes religiosos, quienes negaron la propiedad de nuestra quina de abortar las fiebres tercianas en los pacientes maláricos, con el exclusivo argumento de haber sido aceptada esa propiedad por los jesuitas y por la curia romana. Desde la quina y con ella, hemos caminado por décadas hasta controlar la "causa primera" de la inflamación; no obstante, la complejidad de su patología histoquímica, obliga a lograr más evidencias hasta derrotarla.

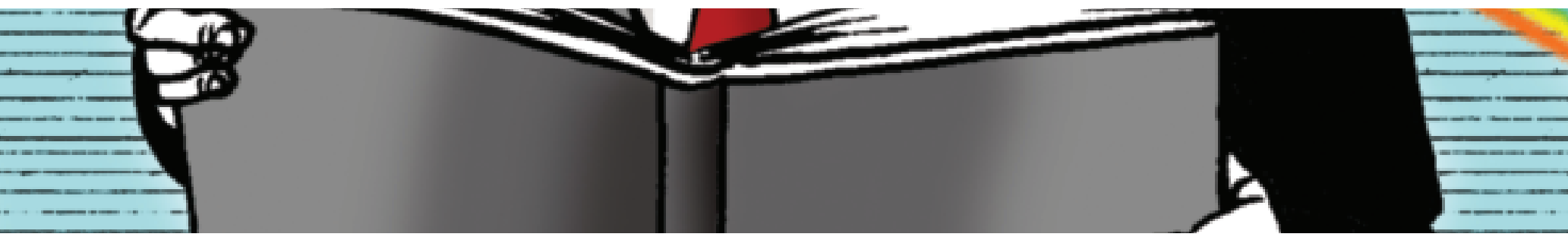


Siendo el arte creación y percepción humanas, exclusivamente tal, no requiere descubrirse ni redescubrirse, sino inventarse, en tanto la sentencia hegeliana anima su esencia: "Lo bello artístico es superior a lo bello natural". Quizá así sea, pues el diálogo del creador (artista) con sus espectadores enriquece la expresión y lenguajes plásticos, da forma y sustancia a la suprema expresión

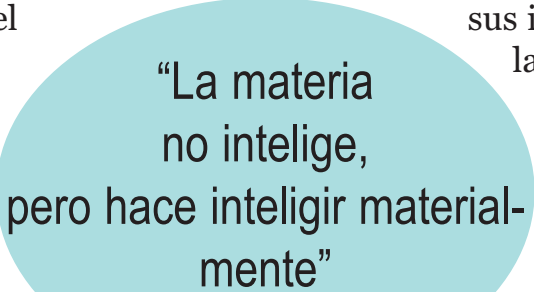

estudio del tiempo y sus implicaciones en la duración de la semivida física y biológica está azotado desde exóticas explicaciones hasta predicciones de de la armonía convertida en mensaje. Se cumple de ese modo la profecía de Zubiri: "La materia no intelige, pero hace inteligir materialmente". En esta arista de mis limitaciones, acudo a Marco Antonio Rodríguez: "Lo peor que puede ocurrirle a un gran artista es que se le comprenda por completo. Algo insondable debe dejar en el espectador después de mirar su obra. Algún resquicio ha de erizar de emotividad y también de sensaciones recónditas." Lo bello en el arte no es exacto, lo creible en el científico es la exactitud.

El artista no está obligado a demostrar sus abstracciones, es más bien un navegante de las utopías; el científialto sostén académico. En la antigüedad se midió el tiempo mediante crónicas paganas o la inserción de intervalos signados por la vida y muerte de dioses, reyes o guerreros briosos, usóse para tal propósito medidas arbitrarias y azarosas: "milenio terrenal", "semana cósmica”, "día sideral”, "año lunar": cada cual apuntando a crear controversias e imprecisiones hasta dejar referencias equívocas sobre la cronología de la historia humana y la historia misma del universo. Aristóteles, Galileo y el mismo Isaac Newton admitían la inmovilidad del universo creado por un Ser Supremo y transitado por un tiempo absoluto, tiempo que estaba separado y era totalmente independiente del espacio. Cerca de co que no liga hipótesis a la aprehensión de la realidad objetiva, será desbordado en el torrente de especulaciones vegetativas. "Para la ciencia lo último será siempre incierto y lo cierto siempre será penúltimo (Pedro Laín). En fin, uno y otro: científico y artista, requieren la evolución conciente de sus procesos

\section{"Para la ciencia} lo último será siempre incierto y lo cierto siempre será penúltimo" observador en movimiento, que se encuentra inextricablemente ligado al espacio y que ningún objeto se mueve a velocidad superior a la de la luz. El pasado era uno y el futuro otro ensarta- dos siglos duró esta hipótesis, hasta que el señor Albert Einsten con su relatividad general, admitió que el tiempo era dif que el tiempo era

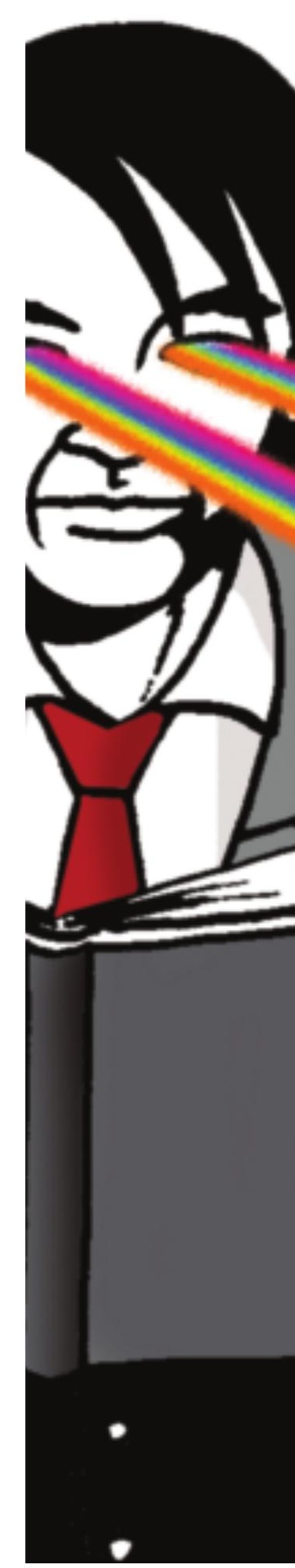


